\title{
REPORT ON USE OF XAD RESINS IN RACING CHEMISTRY
}

\author{
G. H. JOHNSTON, B.Sc., M.C.I.C. \\ Lynn \& Johnston Laboratories Inc., Lachine, Quebec, Canada
}

\begin{abstract}
This report comprises a summary of the work done with XAD resin extraction by racing chemists and reported in the Association of Official Racing Chemists publications. It is apparent that the use of XAD resins is becoming more popular in racing laboratories as a technique for routine screening and also for the extraction of certain conjugated drugs. Most laboratories employ variations on the original Brinkmann Drug-Skreen Technique.
\end{abstract}

Comparisons of the efficiency of extraction of drugs from horse urine by XAD-2 resin and by chloroform column extraction indicate that some drugs can be extracted with equal or greater efficiency by the resin technique.

\section{Introduction}

While a number of $X A D$ resins have been marketed, the XAD-2 resin has found largest use in the field of drug extraction to date.

Amberlite XAD-2 resin is a porous polystyrene nonionic adsorbent manufactured by Rohm \& Haas. This resin is the adsorbent used in the much publicized Brinkmann Drug-Skreen System originally marketed in the early seventies for screening in human drug abuse programmes.

The first recorded attempt at adapting this technique to racing chemistry, by A.O.R.C. Members, was in 1972 by Anita Triola, New York State Racing Commission Laboratory (Triola, 1972). The aim of this study was to use the technique in screening horse saliva samples. Additional experiments involving 23 common drugs encountered in racing samples showed that all could be detected in 25 c.c. saliva samples containing $2 \mu \mathrm{g} / \mathrm{ml}$ of drug. Detection was achieved by Thin Layer Chromatography following elution from the resin with $1: 1$ chloroform: Isopropanol.

During the following two years the three official Canadian laboratories experimented with XAD-2 resin and in Mexico City 1974 they reported the results of their efforts at the Annual Meeting of the A.O.R.C. (Johnston \& Lynn, 1974; Fenwick \& Johnston, 1974; Dollman \& Mann, 1974; Mann, 1974; Maynard \& Polley, 1974; Maynard \& Polley, 1974; Maynard, Park et al, 1974; Maynard, Park et al, 1974; Maynard, Park et al, 1974). Preliminary work with the Brinkmann DrugSkreen apparatus revealed that the technique of passing urine through resin was not readily adaptable to the larger, dirtier horse urine sample. Various means of providing necessary resin to urine contact were attempted along with changes in column design.
As a result of the study the three Canadian laboratories adopted the following $\mathrm{pH} 9.5$ extraction procedure and it is now in use with limited modification in each Canadian laboratory.

\section{Procedure}

1. 100 to $200 \mathrm{ml}$. of urine are buffered to $\mathrm{pH} 9.5$ in a 250 c.c. Erlenmeyer flask to which are added about 7 gm activated XAD-2 resin. (If more than $100 \mathrm{ml}$ are used the urine would be extracted in increments with the same resin).

2. The urine and resin are swirled on a rotary shaker for $10-15$ minutes.

3. The urine is aspirated off through an 80 mesh sieve then the resin is washed into the standard Brinkmann column using dilute pH 9.5 buffer. Note: 80 mesh polypropylene screening is used at bottom of column instead of glass or cotton wool provided by Brinkmann.

4. The resin is sucked dry and rinsed with dilute $\mathrm{pH}$ 9.5 buffer.

5. The column is attached to the standard Brinkmann filter cartridges containing a circle of phase separating paper.

6. The resin is eluted with $5 \times 5 \mathrm{ml}$. increments of $1: 1$ chloroform:ethyl acetate and filtered through the phase separating paper into a $50 \mathrm{ml}$. beaker.

7. Several drops of acid alcohol are added to the solvent which is then evaporated to dryness under a stream of air.

8. The residue is rubbed up with $\mathrm{N} / 20 \mathrm{HCl}$ and separated into different groups for subsequent drug screening. 
9. The acid insolubles remaining are taken up with methanol or hot water and spotted on thin layer plates.

It was found that, compared with continuous column pH 9.5 extraction, drug detection coverage was usually better using XAD-2 resin although extraction efficiency of some drugs was inferior.

Further studies were carried out in 1975 and 1976 using resin techniques to screen for specific drugs. It was found that some conjugated drugs, including the glucuronides of pentazocine and apomorphine are adsorbed by the resin but are not eluted therefrom by the $1: 1$ chloroform:ethyl acetate solvent. However, subsequent elution of the resin with methanol releases the glucuronides, the solution of which can then be evaporated and acid hydrolyzed. This technique can be combined with the above described procedure or can be used on composited samples alone. Work up and differential separation permits the detection and identification of the pure drug by thin-layer and/or gas-liquid chromatography. This technique was successfully employed in the detection of pentazocine, methocarbamol and apomorphine in horse urines from administration experiments (Fenwick, Johnston et al, 1975; Fenwick \& Johnston, 1976), and for positives reported on pentazocine and apomorphine.

It was further found that Frusemide ("furosemide", "LasixR"), which is being used extensively in North America, can be screened for easily by subjecting the resin, after step 6 in the above procedure, to a $10 \%$ acetic acid wash and re-elution with $1: 1$ chloroform:ethyl acetate (Beaumier \& Mann, 1976). Evaporation of the solvent without heat is used to avoid excessive decomposition of the 'furosemide'. Thin-layer chromatography using Mandelin's spray and heat will detect some neutral and acidic drugs which are also released more readily from the resin under these conditions. Subsequent use of the diazo sequential spray provides sensitive detection of 'furosemide'.

It is anticipated that screening of greyhound urine samples in Vermont will be effected with the use of XAD-2 resin (Gardner \& Sawyer, 1976). The procedure to be followed in this case involves the use of a larger glass column containing 5-8 grams of resin. The urine is allowed to filter through the resin, under suction if necessary. After elution the resin is re-cleaned and reused without removal from the columns.

\section{REFERENCES}

Beaumier, P. M. \& Mann, M. J. 1976 'Rapid Method for Determination of Lasix Using XAD-2 Resin' A.O.R.C. 30th Proc. 91-92.*

Brinkmann Instruments (Canada) Ltd. 'Brinkmann Drug-Skreen' Technical Bulletin.

Dollman, A. R. \& Mann, M. J. 1974 'Modified XAD-2 Drug Screening Procedure' A.O.R.C. 28th Proc. 95-99.*

Fenwick, J. D. \& Johnston, G. H. 1974 'Further Evaluation of XAD-2 Resin for Racing Chemistry' A.O.R.C. 28th Proc. 92-94.*

Fenwick, J. D., Johnston, G. H. \& Lynn, S. C. 1975 'Further Studies on Pentazocine' A.O.R.C. 29th Proc. 58-59."

Fenwick, J. D. \& Johnston, G. H. 1976 'Experiments in the Application of XAD-2 Resin Adsorption to Apomorphine Screening' A.O.R.C. 30th Proc. 44-45.*

Gardner, J. \& Sawyer, H. 1976 'XAD-2 Resin Extraction Study' A.O.R.C. 30th Proc. yet to be published."

Johnston, G. H. \& Lynn, S. C. 1974 'Preliminary Report on XAD-2 Resin Research' A.O.R.C. 28th Proc. 83-89."

Mann Testing Labs. Ltd. 1974 'Acid Hydrolysis Procedure for Conjugated Drugs' A.O.R.C. 28th Proc. 100."

Mann, M. J. 1976 'A.O.R.C. Research Committee Report - XAD-2 Resin in 'Racing Questionnaire' ' A.O.R.C. 30th Proc. 17-19.*

Maynard, G. E. \& Polley, G. L. 1974 'XAD-2 Resin Study No. 1 Preliminary Examination of Drug Extraction Using XAD-2 Resin with a Modification of the Brinkmann System Using Small $30 \mathrm{ml}$. Samples' A.O.R.C. 28th Proc. 101-109.* 
Maynard, G. E. \& Polley, G. L. 1974 'XAD-2 Resin Study No. 2. Application of XAD-2 Resin Adsorption to Routine Testing' A.O.R.C. 28th Proc. 110-112."

Maynard, G. E., Park, J. M. \& Smith, J. G. 1974 'XAD-2 Resin Study No. 3. Extraction of Three Indicator Drugs with Resin Adsorption Extraction Using Normal (200 ml.) Solution Samples' A.O.R.C. 28th Proc. 113-116.*

Maynard, G. E., Park, J. M. \& Polley, G. L. 1974 'XAD-2 Resin Study No. 4. Comparative Extractability of a Broad Spectrum of Drugs Using Resin Adsorption and Solvent Extraction Methods' A.O.R.C. 28th Proc. 117-124."

Maynard, G. E., Park, J. M. \& Polley, G. L. 1974 'XAD-2 Resin Study No. 5. Extractability of a Broad Spectrum of Drugs from Equine Urine Using a Resin Adsorption Method' A.O.R.C. 28th Proc. 125-131.*

Triola, Anita 1972 The Application of Amberlite XAD-2 Adsorbent for Racing Analysis' A.O.R.C. 26th Proc. 107-109.*

\title{
FOOTNOTE
}

- PROCEEDINGS OF ASSOCIATION OF OFFICIAL RACING CHEMISTS are not available to non-members of that Association, and application for details should be made to the Hon. Secretary, A.O.R.C., Dr. MARGARET A. SULLIVAN, Ph.D., VALLEY RACING LABORATORIES, P.O. BOX 5711, PHOENIX, ARIZONA 85010, U.S.A.

\section{RESEARCH AND IDENTIFICATION OF TRANQUILLIZERS - USE OF RETENTION INDEX:

\author{
D. COURTOT, Eng.Dr.Biochem.
}

Laboratory for Pharmacy and Toxicology, Ecole Nationale Vétérinaire, (National School for Veterinary Studies), 2 quai Chauveau, 69337 LYON Cedex I, France

\begin{abstract}
At the request of the Service des Haras, our laboratory works on the toxicological problems of the sport-horse. These studies have resulted in the setting up of an anti-doping control for equestrian competitions of various types, not only flat racing.

During events, horses must be calm and docile to the riders' order. Frequently, the latter use tranquillizers to try and win events. The analytical method for the research and identification of these compounds is described.

The technique involves successively:

1. alkalinisation of the sample - saliva, blood or urine after enzymatic hydrolysis.

2. extraction with diethyl ether - the recovery is $70 \%$ to $90 \%$ depending upon the drug.

3. determination by gas-liquid chromatography with use of a retention index for qualitative analysis.

We can detect up to fifteen tranquillizers in any one sample, even when present at such low concentrations as found in saliva.

The use of the retention index is a reliable method for qualitative analysis. For example, the method has been used for three years, during which period the retention index of acetylpromazine remained at $3240 \pm 7$. The chromatographic analysis was performed on $3 \%$ OV-17 at $290^{\circ}$.
\end{abstract}

